\title{
Isolation and Characterization of Highly Effective Phytate-Mineralizing Klebsiella pneumonia Strain MK1C Adapted to Arid and Semiarid Conditions from Calcareous Soil
}

\author{
Mahrous M. Kandil ${ }^{1}$
}

\begin{abstract}
This study aimed to isolate and identify highly adapted and highly efficient phytate-mineralizing bacteria from calcareous soil located in northern area of Egypt of arid and semiarid climate conditions. Using direct pour plate method, NBRIP medium was supplemented with phytate $(5.0 \mathrm{~g} / \mathrm{L})$. The isolate showed the largest halo zone was further studied for its effectiveness in mineralizing phytate. The newly isolated strain was identified through the sequencing and the analysis of its nearly full 16S rRNA gene and was identified as Klebsiella pneumonia strain MK1C with GenBank accession number KU358675 based on BLASTn database. On liquid NBRIP culture, Klebsiella pneumonia strain MK1C showed high growth that was associated with a significant reduction of its $\mathrm{pH}$ from 6.8 to 4.7 and up to 5 times higher production of organic acids compared to uninoculated treatments. As a result, more than $50 \%$ of the organic phosphorus of added phytate was released as inorganic phosphorus. This strain could be an excellent dual-biofertilizer for both phytate mineralization and dinitrogen fixation. This is especially important for soils with poor conditions such as calcareous soils or in areas of arid and semiarid climate conditions where this strain and its related species are highly adapted.
\end{abstract}

Keywords: Phytate, Phosphate, mineralizing, Klebsiella pneumonia

\section{INTRODUCTION}

Phytate or phytic acid (myo-inositol $(1,2,3,4,5,6)$ hexakisphosphoric acid) is the storage of organic phosphorus in plant tissues and seeds as it represents 60 to $90 \%$ of its organic phosphorus (Harland and Morris 1995; Reddy et al. 1982). As storage of phosphorus, phytate $\left(\mathrm{C}_{6} \mathrm{H}_{17} \mathrm{NaO}_{24} \mathrm{P}_{6}\right)$ reaches soils as organic forms through plant remains, manures, and composts. Phytate is a strong chelator for micronutrients such as $\mathrm{Fe}, \mathrm{Zn}$ and cations such as $\mathrm{Ca}$ and $\mathrm{Mg}$ which might reduce their availability for plants. Although phytate is a source of $\mathrm{P}$, it is not suitable for uptake as is and must undergo mineralization by soil microbial community through the production of phytases and phosphatases (Behera et al., 2014; Nash et al., 2014). Available P concentration in soil solution represent only about $0.1 \%$ of its total soil $\mathrm{P}$ (Ram et al., 2015). Therefore, an annual application of superphosphate and liquid phosphoric acid is inevitable to restock $\mathrm{P}$ availability shortage in soils. However, about $90 \%$ of this annually added $\mathrm{P}$ is usually fixed in soils and becomes unavailable for plants (Nash et al., 2014; Richardson and Simpson, 2011; Sharma et al., 2013). It has been reported that over fifty million ton of phytate reaches soils through produced and composted fruits and plant remains annually. This represents about $70 \%$ of commercially worldwide produced inorganic phosphorus fertilizers (Mullaney and Ullah, 2007). Also, one of the problems with phytate in soils is its strong binding affinity to essential minerals, forming insoluble phytate-minerals complexes, and limiting their availability for plants uptake. This mandates exploration for more efficient microorganisms that can be used as biofertilizers to mineralize plant remains and animal manures. The use of degrading and mineralizing microorganisms is an alternative solution to reduce the use of inorganic $\mathrm{P}$ fertilizers must be explored to reduce environmental pollution.

Phosphate solubilizing microorganisms employ various mechanisms, including the production of organic acids, phytase, and phosphatase, which improve the availability of insoluble inorganic and organic phosphorus (Chen et al., 2014; Kumar et al., 2013; Oteino et al., 2015; Richardson and Simpson, 2011; Sharma et al., 2013). While some isolated strains have been found to be plant host specific (Kundu et al., 2002), others have multifunctional mechanisms for $\mathrm{P}$ solubilization (Park et al., 2011; Vassileva et al., 2010). In addition, it has been reported that proton production during ammonium assimilation is another mechanism for phosphate solubilization by microorganisms (Illmer and Schinner, 1995; Illmer et al., 1995).

It has been reported that seed inoculation or sidedressing crops with PDB promoted plant growth and increased crop yields (Anil and Lakshmi, 2010; Mehrvarz et al., 2008; Mehta and Nautiyal, 2001). However, phosphorus solubility and availability for crops is a continuously major issue triggering extensive research for the best strategies to reduce its fixation to soils and increase its availability for plants. Few reports have been published on the isolation and identification of PDB from Egyptian soils (Hesham and

${ }^{1}$ Department of Soil and Water Science, Faculty of Agric.,

Alexandria University, Alexandria 21545, Egypt.

Email: mahrous.kandil@alexu.edu.eg

Received October 22,2017, Accepted December 06, 2017 
Mohamed, 2011; Taha et al., 1969); with no strains isolated from Egyptian calcareous soils. Therefore, the isolation and characterization of new PDB recently became crucial toward finding effective and highly adapted strains for a potential use as a P-biofertilizer alternative to expensive and environment damaging inorganic phosphorus fertilizers. It is expected to have a shortage in inorganic phosphorus fertilizers Worldwide as the $\mathrm{P}$ reserve became limited and its production peak $\mathrm{P}$ had been reached three decades ago (Kirkby and Johnston, 2009). It is well known that phosphate is strongly bound to the soil solid phase and only taken up by the plant roots as $\mathrm{H}_{2} \mathrm{PO}_{4}{ }^{-}$or $\mathrm{HPO}_{4}{ }^{2-}$ ions. To be beneficial source of $\mathrm{P}$, phytate must be dissolved in the soil solution and the ester bond must be split. The mechanism of this split process is still not fully understood whether includes enzymatic or physical reaction.

The main purposes of this study are 1) to isolate and characterize phytate-degrading bacteria from calcareous soil, 2) to determine the possible mechanisms employed by isolated bacteria to mineralize phytate.

\section{MATERIALS AND METHODS}

\subsection{Soil}

Bacterial strains were isolated from soil sample that was collected from the surface layer $(0-20 \mathrm{~cm})$ using an acid washed stainless steel hand shovel at the Research Farm of Agriculture College, Foukah, Marsa Matrouh, at the North Western Coast of Egypt. For microbiological use, a fresh sample was transported on ice to the laboratory and kept at $4{ }^{\circ} \mathrm{C}$ for $24 \mathrm{~h}$ before being used for bacterial isolation. Soil sample was subject to analysis as described elsewhere (Kandil, 2017).

\subsection{Culture Media}

While there are more than one medium well known to be used for isolation of phosphate solubilization microorganisms, the National Botanical Research Institute's Phosphate (NBRIP) growth medium (Nautiyal, 1999) was used. The NBRIP medium contained glucose $(10.0 \mathrm{~g})$, phytic acid sodium salt (5.0 $\mathrm{g}), \mathrm{MgCl}_{2} \cdot 6 \mathrm{H}_{2} \mathrm{O}(5.0 \mathrm{~g}), \mathrm{MgSO}_{4} \cdot 7 \mathrm{H}_{2} \mathrm{O}(0.25 \mathrm{~g}), \mathrm{KCl}$ $(0.2 \mathrm{~g}),\left(\mathrm{NH}_{4}\right)_{2} \mathrm{SO}_{4}(0.1 \mathrm{~g})$, and agar $(15.0 \mathrm{~g})$ per liter of distilled water. The $\mathrm{pH}$ of media was adjusted to 7.0 before autoclaving at $121{ }^{\circ} \mathrm{C}$ for $20 \mathrm{~min}$. Phytic acid solution was filter sterilized $(0.22 \mu \mathrm{m}$ syringe PFTE) and added to medium after cooling to avoid release of orthophosphate during autoclaving. Glucose was filtersterilized by using $0.22 \mu \mathrm{m}$ PFTE filter membranes and was added to media after cooling to $45^{\circ} \mathrm{C}$. Same medium, but liquid was used to measure the effectiveness of isolated strains in phytate degradation. Another rich medium; Luria-Bertani (LB) medium containing glucose $(10.0 \mathrm{~g})$, yeast extract $(5.0 \mathrm{~g}), \mathrm{NaCl}$ $(5.0 \mathrm{~g})$, and agar $(18.0 \mathrm{~g})$ per liter of distilled water was also used for isolates purification and differentiation. All chemicals used in this study were reagent grade or better.

\subsection{Isolation of Phytate Degrading Bacteria}

The direct pour-plate method was used to isolate bacteria mineralizing phytate from the above described soil. Ten-fold serial dilutions (from $10^{-1}$ to $10^{-5}$ ) of soil were made using $0.85 \%$ sterile $\mathrm{NaCl}$ solution and pourplated onto prepared NBRIP medium described above. Plates were incubated and for 7 days at $28{ }^{\circ} \mathrm{C}$. Plates were monitored daily for clearing zones. Individual colonies in clearing zone areas were transferred and streaked multiple times onto solid NBRIP supplemented with phytate for purification. Colonies were streaked on LB medium for ensuring purity. To confirm the capability of purified isolates to degrade phytic acid, diameter of halo zone and colony must be measured. A single colony of purified isolates was transferred by sterilized wood toothpicks and simultaneously stabbed into NBRIP solid media. Plates were incubated at $28{ }^{\circ} \mathrm{C}$ and colonies monitored for the appearance of halo zones. Diameter of both colony and halo zone was measured daily and used to calculate solubility index using the following equation:

$$
P y S I=H a l Z \mathrm{~d} / C l n \mathrm{~d}
$$

where PySI is the solubility index, HalZd is the halo zone diameter $(\mathrm{mm})$, and $C l n d$ is the colony diameter (mm).

Strains showing a high solubility index were selected for further study. Pure cultures were transferred to LB slants and kept in the refrigerator at $4{ }^{\circ} \mathrm{C}$ to be used for further studies. Pure cultures were also preserved in $20 \%$ sterile glycerol and stored at $-70{ }^{\circ} \mathrm{C}$ for long term storage.

\subsection{Colony-PCR of 16s rRNA Gene of Phytate Degrading Isolates}

To identify phytate mineralizing bacteria, basic phenotypic characteristics were measured. Also the $16 \mathrm{~S}$ rRNA gene of selected isolates was amplified according to Weisburg et al., (1991). In this method, forward primer 27f (5`-AGAGTTTGATCMTGGCTCAG-3`) and reverse primer 1492r (5'CTACGGCTACCTTGTTACGA-3') (Integrated DNA Technologies, Coralville, Iowa) were used. The recently developed direct colony-PCR method was used without going through the traditional tedious method of DNA extraction and purification. A pure single colony of each isolate was selected, picked with a $1-\mu 1$ sterile inoculating loop (Fisher Scientific, Pittsburgh, PA), and 
inserted in a labeled PCR tube. Tubes contained the PCR mixture $(50 \mu \mathrm{l})$ of sterilized Millipore nuclease free water $(40.5 \mu \mathrm{l}), 10 \mathrm{X}$ PCR buffer $(5 \mu \mathrm{l})$, dNTPs $(2$ $\mu \mathrm{l}), 27 \mathrm{f}$ primer $(1 \mu \mathrm{l}), 1492 \mathrm{r}$ primer $(1 \mu \mathrm{l})$, and Choice Taq Polymerase $(0.5 \mu \mathrm{l})$. Tubes were shaken and centrifuged for $20 \mathrm{sec}$. PCR was performed using an MJ research PTC 100 (MJ Research, Waltham, Mass., USA) thermocycler. In general, the PCR program was as follow: initial denaturing step for $95{ }^{\circ} \mathrm{C}$ for $15 \mathrm{~min}$, followed by 34 cycles of $95{ }^{\circ} \mathrm{C}$ for $30 \mathrm{sec}, 57{ }^{\circ} \mathrm{C}$ for 45 sec, and $72{ }^{\circ} \mathrm{C}$ for 1.5 min with a final extension step for $6 \mathrm{~min}$ at $72{ }^{\circ} \mathrm{C}$ in an automated thermal cycler then a storing step at $4{ }^{\circ} \mathrm{C}$.

\subsection{Purification and Sequencing of 16S rRNA Gene}

Before sequencing, PCR products were examined for successful amplification by using gel electrophoresis as described elsewhere (Kandil et al., 2015). The PCR products of the 16S rRNA gene were purified using QIAquick PCR purification kit (Qiagen, Valencia, CA, USA). Before sending DNA samples for sequencing, samples were examined on gel electrophoresis to confirm their purity and presence. DNA concentration was determined by Qubit 2.0 fluorometer as described by standard protocol (Invitrogen, Life technologies, Carlsbad, CA). Based on DNA concentration of each sample, proper volume was determined to be used for DNA sequencing template. Both DNA strands were sequenced based on Sanger sequencing standards (ACGT, Inc, Wheeling, IL) using the $27 \mathrm{f}$ and $1492 \mathrm{r}$ primers.

\subsection{Identification and Nomenclature of Phytate Degrading Isolates}

Consensus sequence contigs of both strands sequences was generated using BioEdit software (Hall, 1999) and compared with GenBank database of nucleotides by using the BLASTn algorithm (Altschul, et al., 1990). Isolated strains were named based on its identical match or highest in similarity in database. A Phylogenetic tree was generated for interrelationships among the strains using MEGA4 or its latest updated software (Tamura et al., 2007).

\subsection{Quantitative Analysis of Phytate Degradation}

The efficiency of isolated strain in degrading phytate as the only organic phosphorus source was determined. Strains were grown in NBRIP liquid medium supplemented with phytic acid sodium salt solution (1.0 $\mathrm{g} / \mathrm{L})$. This solution was filter sterilized $(0.22 \mu \mathrm{m}$ syringe PFTE) and added to medium after cooling to avoid release of orthophosphate during autoclaving. All treatments $(125 \mathrm{~mL}$ in $250 \mathrm{~mL}$ conical flasks) were in triplicate, and included negative and positive controls that were incubated at $28{ }^{\circ} \mathrm{C}$. This experiment was conducted in 250-mL Erlenmeyer flasks containing 125
$\mathrm{mL}$ of sterilized NBRIP medium and incubated at $28{ }^{\circ} \mathrm{C}$ for $15 \mathrm{~d}$ on a rotary shaker at $120 \mathrm{rpm}$. Triplicate flasks including blanks were sampled nearly every other day under aseptic conditions for measurement of $\mathrm{OD}_{600}, \mathrm{pH}$, total organic acids, and released soluble P. About $5 \mathrm{~mL}$ aliquot of culture was decanted aseptically and used for abovementioned measurements. Culture $\mathrm{pH}$ was measured in the suspension without centrifugation or filtration. To measure $\mathrm{OD}_{600}$, decanted samples were left to stand for 15 min to allow any precipitates other than bacterial cells to settle out of solution and the upper solution was used for measurement of $\mathrm{OD}_{600}$.

\subsection{Determination of Released Inorganic Phosphorus}

To measure released soluble inorganic $P$, same decanted above described samples were used. It is not a surprise to state that measuring $\mathrm{P}$ in general is a challenge. This is especially true when we have a mixture of phytate as organic phosphorus and the released inorganic $\mathrm{P}$ due to its degradation. The blue method was chosen for its sensitivity and applicability with the understanding that some level of interference exists. After incubation with pure isolates, samples were centrifuged at $6,000 \mathrm{xg}$ for $15 \mathrm{~min}$ to pellet cell debris and the supernatant was used. The colorimetric blue ammonium molybdate method was used for the determination of soluble $\mathrm{P}$ in supernatant and was measured by spectrophotometer at $882 \mathrm{~nm}$ (Murphy and Riley, 1962). The concentration of released $\mathrm{P}$ in supernatant was calculated against $\mathrm{KH}_{2} \mathrm{PO}_{4}$ standard curve with concentrations ranging from 0 to $2 \mathrm{mg} / \mathrm{L}$. samples showed a concentration above range were diluted and re-measured.

\subsection{Determination of Total Organic Acids}

According to literature, many phosphate dissolving organisms produce organic acids to lower the $\mathrm{pH}$ of its surroundings either in nature of culture media. In this study, the total organic acids was measured directly in clear supernatant after centrifugation and filtration using spectrophotometer at $220 \mathrm{~nm}$ (Sokullu et al., 2010) and values were compared to uninoculated control samples. Specific organic acids were not determined at this stage of this study.

\section{RESULTS AND DISCUSSION}

\subsection{Successful Isolation of Phytate Degrading Bacteria from Calcareous Soil}

The main purpose of this study is to isolate bacteria degrading phytic acid sodium salt. Using direct pour plate method is advantageous to isolate existing bacteria with the ability to degrade phytate rather than those developed their ability due to genetic evolution. In this experiment, several halo zones were recognized on NBRIP medium. Almost all colonies within produced 
halo zones were transferred and streaked onto fresh NBRIP and LB plates several times. Several pure isolates having distinct morphological features were tested for their ability to solubilize phytic acid sodium salt (5.0 g/L). Colonies showed no clearing zones or lost their ability to clear phytate supplemented plates were eliminated. As a result, few pure colonies forming halo zone on NBRIP solid plates supplemented with phytate were isolated as shown in Figure 1.

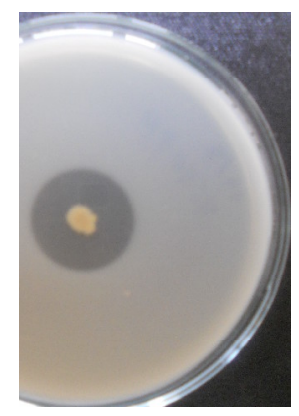

Fig. 1. Formation of halo zone by phytatemineralizing isolate on NBRIP solid medium supplemented with phytate $(5.0 \mathrm{~g} / \mathrm{L})$

3.2 Solubility Index for Selection of Effective PDB strains

Solubility index is a value indicating the effectiveness of microorganisms in the production of certain substances with certain function such as antibiotics, enzymes or toxins. It depends on forming a halo or clearing zone around the bacterial colony indicating the solubility or degradability of the substance under investigation. This technique has been widely used and successfully applied for the isolation of phosphate dissolving microorganisms and for the screening of plant growth promoting microorganisms. In general, larger diameter of halo zone indicates higher effectiveness in phosphate dissolving due to the diffusion of produced organic acids, enzymes, protons, or siderophore (Illmer et al., 1995; Nautiyal, 1999; Pikovskaya, 1948). In this present study, the phytate solubility index $(P y S I)$ for selected isolates on NBRIP media supplemented with phytic acid sodium salt (5.0 $\mathrm{g} / \mathrm{L})$ was calculated as described (Eq.1) from the diameter of the microbial colony and halo zone as shown in Figure 1. Data of this study showed that solubility index varied among isolates and over incubation time as reported previously (Kandil, 2017). As shown in Figure 2, the solubility index $(P y S I)$ was not a fixed value for each isolate but has changed during incubation period from a higher value after 2 days to a lower value after 3-4 days of incubation. Data of this study supports that the decrease in the PySI ratio was due to a continuous growth of the bacterial colony and the increase of its diameter that is juxtaposed by a continuous but obviously less increase in the diameter of the clear zone. Therefore, a short incubation period of 3 to 4 days is reasonable for selecting phosphate dissolving bacteria rather than waiting for a week to decide. Based on the high solubility index of phytate on NBRIP media, one isolate was selected for further studies and identification.

\section{3 purification and Sequencing of 16S rRNA Gene}

As described above, 16S rRNA gene was amplified using colony PCR method. Validity and quality of $16 \mathrm{~S}$ rRNA product was examined by gel electrophoresis as described. This step was followed by purification by QIAquick PCR purification kit to ensure high quality product at sequencing. The concentration of purified 16S rRNA was measured to determine optimum sample volume needed for optimum sequencing. Figure 3 shows the agarose gel with 16S rRNA before (lanes 1 and 2) and after (lanes 3 and 4) purification compared to a known positive (lane 5) and blank (lane 6) samples. Data shows that the colony-PCR procedure was successful and samples were pure and proper concentration for high quality sequencing. As shown, the product is about $1500 \mathrm{bp}$ as compared to the top band of a $100 \mathrm{~kb}$ ladder indicating that the gene amplified is the targeted $16 \mathrm{~S}$ rRNA.

\subsection{Taxonomic Identification of Phytate Degrading Strain}

Some phenotypic characteristics were measured by microscope and physiological tests. Cells of isolated strain were found to be Gram-negative, nonmotile, encapsulated, lactose-fermenting, facultative anaerobic, rod-shaped bacterium, urea positive, and non-spore forming. The taxonomic identity of the isolated efficient phytate-degrading strain was determined by near full length sequence analysis of its 16S rRNA gene (Fig.4). Based on BLASTn searches, the sequences of the $16 \mathrm{~S}$ rRNA genes of the isolate ranged from 97 to $99 \%$ identical to several strains in the genomic database. The best match for isolate MK1C (99\% similarity) were Klebsiella pneumoniae QLR-8 (KM096437.1), Klebsiella pneumoniae isolate YNUCC0237 (AY552753.1), Klebsiella sp. SCAUS56 (KF836054.1), and Klebsiella variicola strain C109 (HQ407284.1), and Klebsiella sp. G3 that showed 97\% similarity to isolate MK1C. This strain was taxonomically classified as Klebsiella sp. strain MKIC based on its $16 \mathrm{~S}$ rRNA gene sequence and was given a GenBank accession number KU358675. 


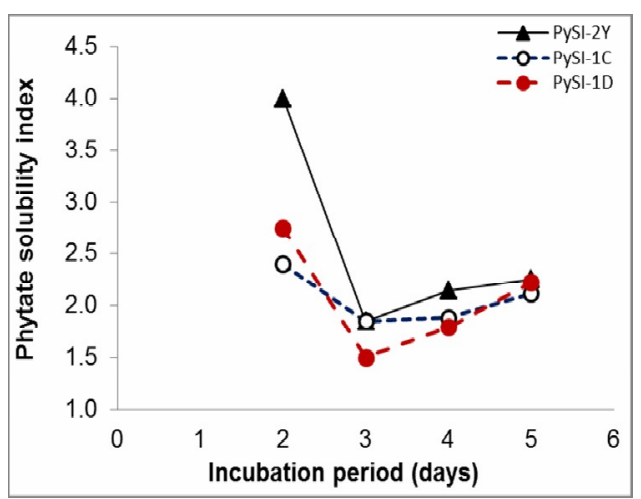

Fig. 2. Phytate solubility index (PySI) for three isolates cultured on NBRIP as labeled. Diameters of halo zones and colonies were used for PySI calculation as in Eq.1

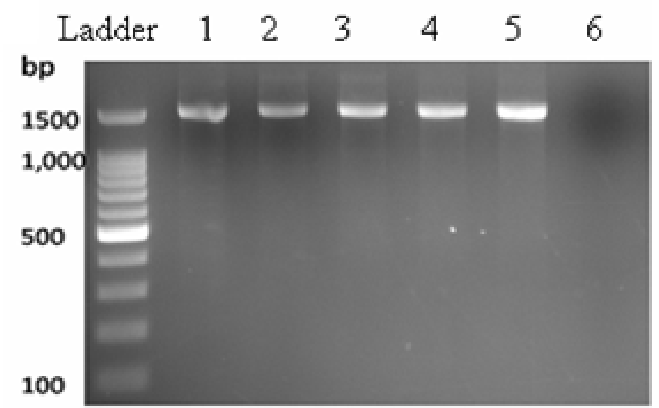

Fig. 3. Agarose gel with 16S rRNA bands of two isolates before (lanes 1 and 2 ) and after (lanes 3 and 4) purification compared to that of a known strain as positive (lane 5) and that of a blank (lane 6) samples

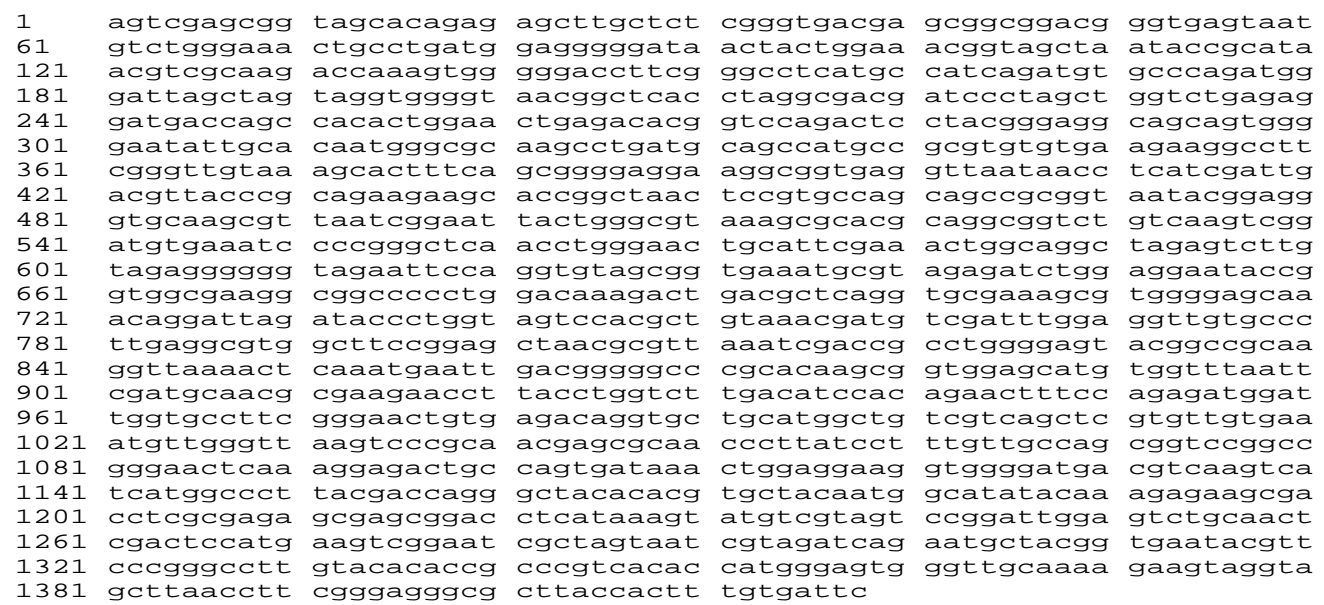

Fig. 4. The near full-length sequence of the 16S rRNA gene of isolated Klebsiella sp. strain MKIC

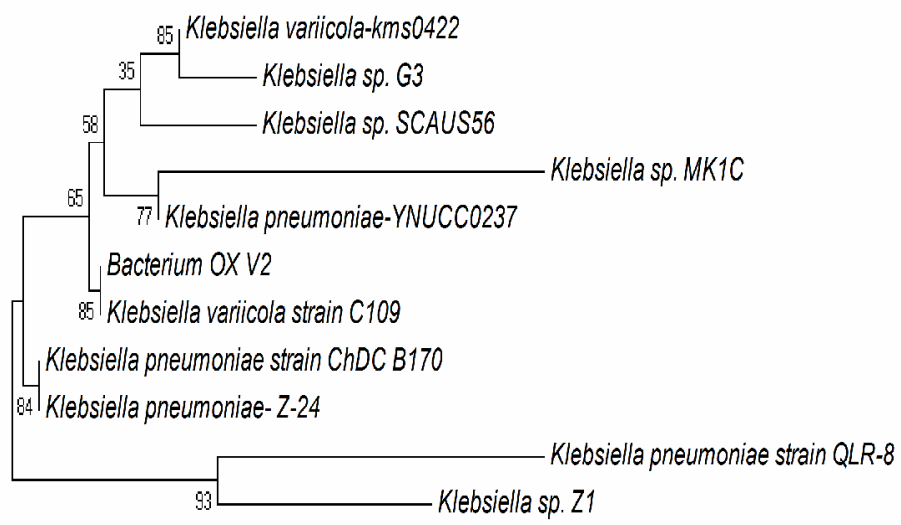

0.0015

Fig. 5. Evolutionary relationships of taxa for Klebsiella sp. strain MKIC 
The evolutionary history was inferred using the UPGMA method (Sneath and Sokal 1973). The percentage of replicate trees in which the associated taxa clustered together in the bootstrap test (100 replicates) is shown next to the branches (Felsenstein 1985). The tree is drawn to scale, with branch lengths in the same units as those of the evolutionary distances used to infer the phylogenetic tree. The evolutionary distances were computed using the Jukes-Cantor method (Jukes and Cantor 1969) and are in the units of the number of base substitutions per site. The analysis involved 11 nucleotide sequences. All positions containing gaps and missing data were eliminated. Evolutionary analyses were conducted in MEGA7 (Kumar et al. 2016).

To the best of our knowledge, this is the first time that Klebsiella sp. strain to be isolated from calcareous soil from Egypt. Worldwide, closely related species such as Klebsiella terrigena (Greiner and Carlsson, 2006), Klebsiella sp. strain ASR1 (Sajidan et al 2004), and Klebsiella pneumoniae 9-3B (Escobin-Mopera et al. 2012), Klebsiella sp. Db- 3fj711774.1 (Mittal et al. 2012) have previously been isolated and reported to degrade phytate.

\subsection{Mechanisms of Phytate Solubilization}

To quantitatively measure the effectiveness and mechanisms of identified strain to degrade and mineralize phytate, the NBRIP liquid medium has been used. In this experiment, the growth of the strain and its ability to mineralize phytate to inorganic phosphorus were measured. Also the culture $\mathrm{pH}$ and the total organic acids were measured in the same sample after filtration. Measuring those 4 parameters in the same sample will allow more succinct understanding of not only the efficiency of the strain but its mineralizing mechanisms of phytate. In this experiment, NBRIP liquid medium supplemented with $1.0 \mathrm{~g} / \mathrm{L}$ phytic acid sodium salt was inoculated with Klebsiella sp. strain MK1C and incubated as described above. To evaluate the ability of the isolated strain to use phytate as both carbon and phosphorus sources, some treatments were suplemented with glucose as a source of carbon, while some were not. As Figures 6A, B, and C show, only treatments supplelemnted with glucose showed bacteria growth, disappearence of the white precipitate of phytate, decrease in culture $\mathrm{pH}$, production of organic acids and as a result, a significant release of inorganic $\mathrm{P}$ as explained below.

As shown in Figure $6 \mathrm{~A}$, the growth $\left(\mathrm{OD}_{600}\right)$ of Klebsiella sp. strain MKIC was associated with a significant reduction of its culture $\mathrm{pH}$ from 6.8 initially to about 4.7 during incubation. This indicated that reducing the $\mathrm{pH}$ might be one of the mechanisms of mineralizing phytate. It is possible that this strain produced some organic acids to reduce the $\mathrm{pH}$ of its habitat. To confirm, the culture content of total organic acids was measured at $220 \mathrm{~nm}$ by spectropotometer after filtering through $0.22 \mu \mathrm{m}$ PFTE filters and compared to uninoculated control as shown in Figure 6B. As shown, the ratio of total organic acids produced by Klebsiella sp. strain MKIC was significally increasing with the growth of the strain up to 6 times more than that of uninoculated control treatments.
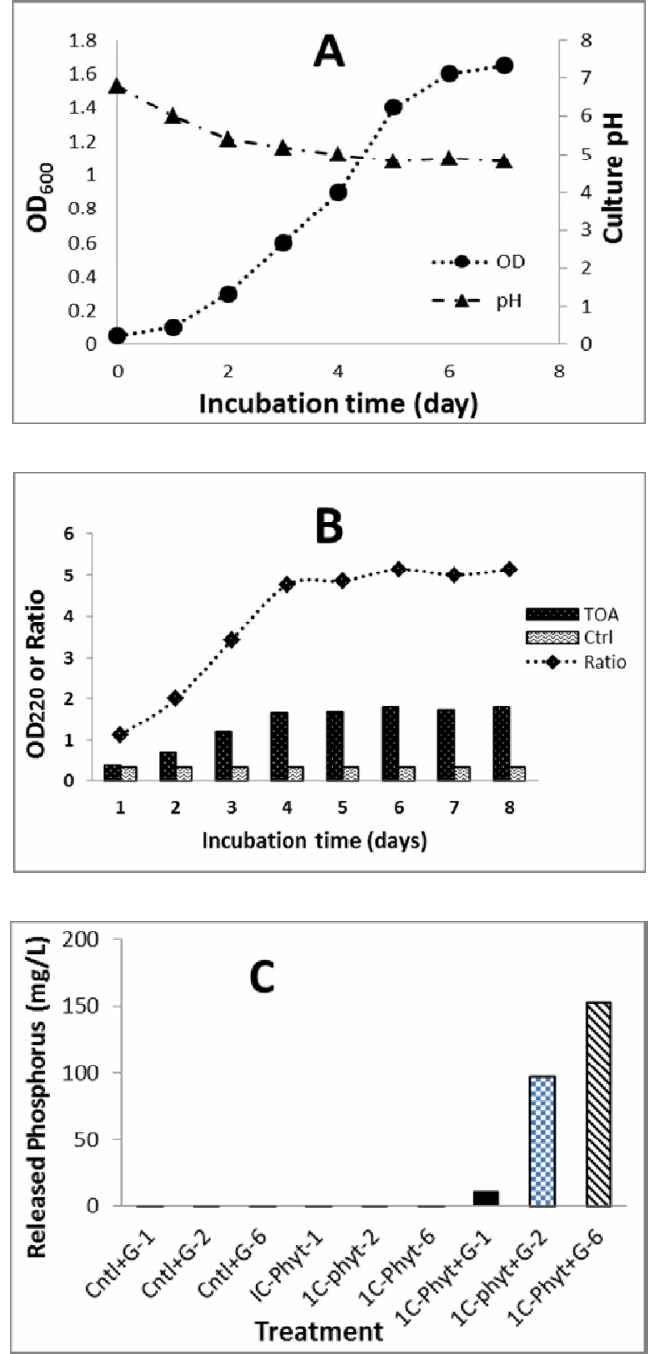

Fig. 6. The grwoth of Klebsiella sp. strain MKIC on NBRIP medium supplemented with phytate (1000 $\mathrm{mg} / \mathrm{L}$ ) and reduction of its $\mathrm{pH}(6 \mathrm{~A})$; production of total organic acids (TOA) compared to control treatments (6B), and release of inorganic phosphorus in treatments supplemented with glucose as a simple carbon source (6C). Legends and treatments are as shown 
As a result, as shown in Figure 6C, Klebsiella sp. strain MKIC was capable of mineralizing phytate and releasing about $70 \%(192 \mathrm{mg} / \mathrm{L})$ of its initial bounded phosphorus content $(282 \mathrm{mg} / \mathrm{L})$ as soluble inorganic phosphorus in treatments supplemented with glucose as a carbon source. Also, Figure 6C shows that the strain was not capable of using phytate as a carbon source and another carbon source such as glucose must be supplemented. It is reported that soil microorganisms were found to dissolve or metabolize phytate through the production of several enzymes, mainly phytase and phosphatase (Greiner, 2004; Illmer et al., 1995; Johri et al., 1999; Kumar et al., 2013). Therefore, It is highly possible that enzymes such as phytase and phosphatase were produced to mineralize phytae. It will be difficult to determine the exact mechanism or differentiate the contribution of enzymes vs organic acids in mineralizing phytae and releasing inorganic phosphorus as a final product. This process requires another set of expirements which was not the intend of this study. Further future studies are needed to answer such questions. This is an agreement with other the solubilization of $\mathrm{P}$ was due to the production of organic acids (Dastager et al., 2010; Illmer and Schinner, 1995; Illmer et al., 1995; Pandey et al., 2006), siderophore (Sharma et al., 2013), indole acetic acids (Sergeeva et al., 2007), phytase (Acu?a and Jorquera, 2011; Konietzny and Greiner, 2004), and protons during ammonia respiration (Illmer and Schinner, 1995; Ramesh et al., 2014; Reyes et al., 2006).

In conclusion, this study aimed to isolate and identify highly adapted and highly efficient phytatemineralizing bacteria from calcareous soil located in northern area of Egypt known to be arid and semiarid climate conditions. The newly isolated strain was identified by nearly its full $16 \mathrm{~S}$ rRNA sequence as Klebsiella sp. strain MKIC. This strain could be excellent dual-biofertilizer for phosphate solubilization and for dinitrogen fixation. This is especially important for soils with poor conditions such as calcareous soils or in areas of arid and semiarid climate conditions where this strain or its related species are highly adapted. Taken together, results of this study are in agreement with those previously confirming the association of the growth of phytate mineralizing bacteria with organic acids production, $\mathrm{pH}$ reduction, enzymes mode of action, and ultimatly inorganic-P release.

\section{ACKNOWLEDGMENTS}

Author is grateful to Prof. Michael Sadowsky, University of Minnesota, USA for his support with a bench space.

\section{REFERENCES}

Acu?a, J.J. and M.A. Jorquera. O.A. Martinez. 2011. Indole acetic acid and phytase activity produced by rhizosphere bacilli as affected by $\mathrm{pH}$ and metals. J. Soil Sci. Plant Nutr. 11:1-12. doi:10.4067/S0718-95162011000300001.

Altschul, S.F., W. Gish, W. Miller, E.W. Myers and D.J. Lipman. 1990. Basic local alignment search tool. J. Mol. Biol. 215(3):403-410.

Anil, K. and T. Lakshmi. 2010. Phosphate solubilization potential and phosphatase activity of rhizospheric Trichoderma spp. Braz. J. Microbiol. 41:787-95. doi:10.1590/S1517-83822010005000031

Behera, B.C., S.K. Singdevsachan, R.R. Mishra, S.K. Dutta and H.N. Thatoi. 2014. Diversity, mechanism and biotechnology of phosphate solubilising microorganism in mangrove-A review. Biocatal. Agric. Biotechnol. 3: 97110. doi:10.1016/j.bcab.2013.09.008

Chen, Y., J.B. Fan, L. Du, H. Xu, Q.H. Zhang and Y.Q. He. 2014. The application of phosphate solubilizing endophyte Pantoea dispersa triggers the microbial community in red acidic soil. Appl. Soil Ecol. 84:235-244. doi:10.1016/j.apsoil.2014.05.014

Dastager, S.G., D.C. Kumaran, D.C. and A. Pandey. 2010. Characterization of plant growth-promoting rhizobacterium Exiguobacterium NII-0906 for its growth promotion of cowpea (Vigna unguiculata). Biologia (Bratisl). 65:197-203. doi:10.2478/s11756-010-0010-1

Escobin-Mopera, L., M. Ohtani, S. Sekiguchi, T. Soni, A. Abe, M. Tanaka, V. Meevootisom and K. Asano. 2012. Purification and characterization of phytase from Klebsiella pneumoniae 9-3B. J. Biosci. Bioeng. 113: 562567.

Felsenstein, J. 1985. Confidence limits on phylogenies: An approach using the bootstrap. Evolution.39:783-791.

Greiner, R. 2004. Degradation of myo-inositol Hexakisphosphate by a phytate-degrading Enzyme from Pantoea agglomerans. Protein J. 23(8):577-585.

Greiner, R. and N.G. Carlsson. 2006. myo-Inositol phosphate isomers generated by the action of a phytate-degrading enzyme from Klebsiella terrigena on phytate. Canad. J. Microbiol. 52(8): 759-768. https://doi.org/10.1139/w06028.

Hall, T.A. 1999. BioEdit: a user-friendly biological sequence alignment editor and analysis program for Windows 95/98/NT, In Nucleic acids symposium series. 41:95-98.

Harl, B.F. and E.R. Morris. 1995. Phytate: A good or a bad food component? Nutr Res. 15(5):733-754.

Hesham, A. and H.M. Mohamed. 2011. Molecular genetic identification of yeast strains isolated from Egyptian soils for solubilization of inorganic phosphates and growth promotion of Corn plants. J. Microbiol. Biotechnol. 2:5561. doi:10.4014/jmb.1006.06045.

Illmer, P. and F. Schinner. 1995. Solubilization of inorganic calcium phosphates-solubilization mechanisms. Soil Biol. Biochem. 27: 257-263. 
Illmer, P., A. Barbato and F. Schinner. 1995. Solubilization of hardly-soluble $\mathrm{AlPO}_{4}$ with P-solubilizing microorganisms. Soil Biol. Biochem. 27:265-270.

Johri, J., S. Surange and C. Nautiyal. 1999. Occurrence of salt, $\mathrm{pH}$, and temperature-tolerant, phosphate-solubilizing bacteria in alkaline soils. Curr. Microbiol. 39:89-93.

Jukes, T.H. and C.R. Cantor.1969. Evolution of Protein Molecules. In Mammalian Protein Metabolism, H.N. Munro (Ed.). pp. 21-132.Academic Press, New York.

Kandil, M.M. 2017. Characterization of Pantoea sp. strain MK1D and Erwinia sp. Strain, MK2Y as tricalcium phosphate dissolving bacteria isolated from calcareous soil. Alex. Sci. Exch. J. 38(2):335-342.

Kandil, M.M., C. Trigo, W.C. Koskinen and M.J. Sadowsky. 2015. Isolation and characterization of a novel Imidacloprid-degrading Mycobacterium sp. strain MK6 from an Egyptian soil. J. Agric. Food Chem. 63:47214727.

Kirkby, E.A. and A.E. Johnston. 2008. Soil and fertilizer phosphorus in relation to crop nutrition. In The Ecophysiology of Plant-Phosphorus Interactions. Hammond, J.P and P.J. Johnston (Eds), pp.177223.Springer: New York, NY, USA,

Konietzny, U. and R. Greiner. 2004. Bacterial phytase: potential application, in vitro function and regulation of its synthesis. Braz. J. Microbiol. 35:11-18. doi:10.1590/S1517-83822004000100002.

Kumar S., G. Stecher, and K. Tamura. 2016. MEGA7: Molecular Evolutionary Genetics Analysis version 7.0 for bigger datasets. Molecular Biology and Evolution. 33:1870-1874.

Kumar, V., P. Singh, M.A. Jorquera, P. Sangwan, P. Kumar, A.K. Verma and S. Agrawal. 2013. Isolation of phytaseproducing bacteria from Himalayan soils and their effect on growth and phosphorus uptake of Indian mustard (Brassica juncea). World J. Microbiol. Biotechnol. 29:1361-1369. doi:10.1007/s11274-013-1299-z.

Kundu, B.S., R. Gera, N. Sharma, A. Bhatia and R. Sharma. 2002. Host specificity of phosphate solubilising bacteria. Indian J. Microbiology. 42:19-21.

Mehta, S. and C.S. Nautiyal. 2001. An efficient method for qualitative screening of phosphate-solubilizing bacteria. Curr. Microbiol. 43:51-56. doi:10.1007/s002840010259

Mittal, A., G. Singh, V. Goyal, A. Yadav and N. Kumarn. 2012. Production of phytase by acidothermophilic strain of Klebsiella sp .Db- 3fj711774.1 using orange peel flour under submerged fermentation. Innovat. Rom. Food Biotechnol. 10:18-27.

Mullaney, E.J. and A.H. Ullah. 2007. Phytases: Attributes, catalytic mechanisms and applications: In Inositol Phosphates: Linking Agriculture and the Environment. Turner, B.L., A.E. Richardson, and E.J. Mullaney (Eds.). pp. 97-110. CABI: Wallingford, UK,

Murphy, J. and I.P. Riley. 1962. A modified single solution method for the determination of phosphate in natural waters. Anal. Chim. Acta. 27:31-36.
Nash, D.M., P.M. Haygarth, B.L. Turner, L.M. Condron, R.W. McDowell, A.E. Richardson, M. Watkins and M.W. Heaven. 2014. Using organic phosphorus to sustain pasture productivity: A perspective. Geoderma, 221222:11-19 doi:10.1016/j.geoderma.2013.12.004.

Nautiyal, C.S. 1999. An efficient microbiological growth medium for screening phosphate solubilizing microorganisms. FEMS Microbiol. Lett. 170:265-270.

Oteino, N., R.D. Lally, S. Kiwanuka, A. Lloyd, D. Ryan, K.J. Germaine and D.N. Dowling. 2015. Plant growth promotion induced by phosphate solubilizing endophytic Pseudomonas isolates. Front. Microbiol. 6:1-9. doi:10.3389/fmicb.2015.00745.

Pandey, A., P. Trivedi, B. Kumar, and L.M.S. Palni. 2006. Characterization of a phosphate solubilizing and antagonistic strain of Pseudomonas putida (B0) isolated from a sub-alpine location in the Indian Central Himalaya. Curr Microbiol. 53:102-107.

Park, J.H., N. Bolan, M. Megharaj and R. Naidu. 2011. Isolation of phosphate solubilizing bacteria and their potential for lead immobilization in soil. J. Hazard. Mater. 185:829-836. doi:10.1016/j.jhazmat.2010.09.095.

Pikovskaya, R.I.1948. Mobilization of phosphorus in soil in connection with the vital activity of some microbial species. Mikrobiologiya. 17:362-370.

Ram, H., S.S. Malik, S.S. Dhaliwal, B. Kumar and Y. Singh. 2015. Growth and productivity of wheat affected by phosphorus- solubilizing fungi and phosphorus levels. Plant Soil Environ. 61: 122-126. doi:10.17221/982/2014PSE

Ramesh, A., S.K. Sharma, M.P. Sharma, N. Yadav and O.P. Joshi. 2014. Inoculation of zinc solubilizing Bacillus aryabhattai strains for improved growth, mobilization and biofortification of zinc in soybean and wheat cultivated in Vertisols of central India. Appl. Soil Ecol. 73: 87-96. doi:10.1016/j.apsoil.2013.08.009

Reddy, N.R., S.K. Sathe and D.K. Salunkhe. 1982. Phytates in legumes and cereals. Adv. Food Res. 28: 1-92. PMID 6299067. doi:10.1016/s0065-2628(08)60110-x.

Reyes, I., A. Valery and Z. Valduz. 2006. Phosphatesolubilizing microorganisms isolated from rhizospheric and bulk soils of colonizer plants at an abandoned rock phosphate mine. Plant Soil. 287:69-75. doi:10.1007/s11104-006-9061-z.

Richardson, A.E. and R.J. Simpson. 2011. Soil microorganisms mediating phosphorus availability update on microbial phosphorus. Plant Physiol. 156: 989-996. doi:10.1104/pp.111.175448

Sajidan, A., A. Farouk, R. Greiner, P. Jungblut, E.C. Müller, and R. Borriss. 2004. Molecular and physiological characterisation of a 3-phytase from soil bacterium Klebsiella sp. ASR1. Appl. Microbiol. Biotechnol. 65:110-118. https://doi.org/10.1007/s00253003-1530.

Sergeeva, E., D.L.M. Hirkala and L.M. Nelso, 2007. Production of indole-3-acetic acid, aromatic amino acid aminotransferase activities and plant growth promotion by 
Pantoea agglomerans rhizosphere isolates. Plant Soil. 297:1-13. doi:10.1007/s11104-007-9314-5

Sharma, S.B., R.Z. Sayyed, M.H. Trivedi and T.A. Gobi. 2013. Phosphate solubilizing microbes: sustainable approach for managing phosphorus deficiency in agricultural soils. Springerplus. 2:587.

Sneath, P.H.A. and R.R. Sokal. 1973. Numerical Taxonomy. Freeman, San Francisco.

Sokullu, E., İ.M. Palabıyı, F. Onur and I.H. Boyacı. 2010. Chemometric methods for simultaneous quantification of lactic, malic and fumaric acids. Eng. Life Sci. 10: 297303. doi:10.1002/elsc. 200900080.

Taha, S. M., S.A.Z. Mahmoud, A.H. El-Damaty and A.M. Abd El-Hafez. 1969. Activity of phosphate-dissolving bacteria in Egyptian soils. Plant Soil. 31:149-160.
Tamura, K., J. Dudley, M. Nei, S.Kumar. 2007. MEGA4: molecular evolutionary genetics analysis (MEGA) software version 4.0. Mol. Biol. Evol. 24:1596-1599. doi:10.1093/molbev/msm092.

Vassileva, M., M. Serrano, V. Bravo, E. Jurado, I. Nikolaeva, V. Martos and N. Vassilev. 2010. Multifunctional properties of phosphate-solubilizing microorganisms grown on agro-industrial wastes in fermentation and soil conditions. Appl. Microbiol. Biotechnol. 85:1287-1299. doi:10.1007/s00253-009-2366-0.

Weisburg, W.G., S.M. Barns, D.A. Pelletier and D.J. Lane. 1991.16S ribosomal DNA amplification for phylogenetic study. J. Bacteriol. 173:697-703.

\section{الملخص العربي}

\section{عزل وتوصيف سلالة كليبسيلا نيمونيا عالية الكفاعة في معدنة الفيتات والمتأقمة للظروف الجافة وشبه الجافة من الار اضي الجيرية \\ محروس قنديل}

معنوياً و الذي ارتبط مع إنخفاض كبير في درجة الحموضة

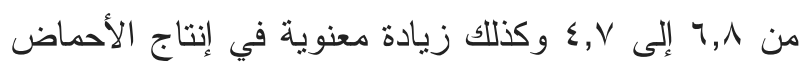
العضوية تصل إلى ه أضعاف المعاملات غيــر الملقحــة.

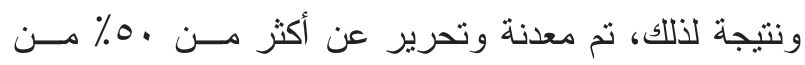

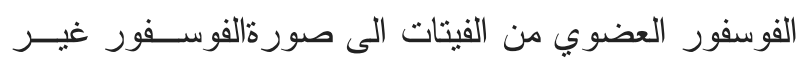

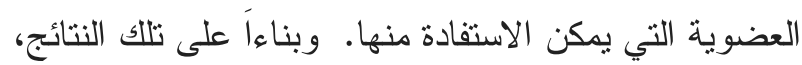
يحتمل أن تكون هذه السلالة مزدوجة الاستفادة كسماد حيوي لئي

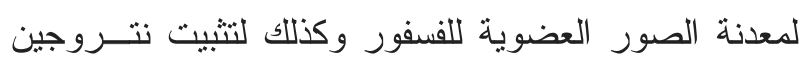
الهو اءالجوي كما هو معروف. وتكتسب نتائج هذه الدر اســـة

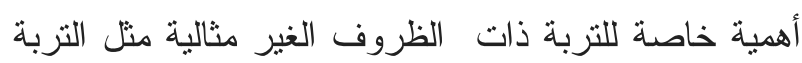

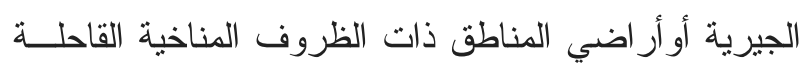

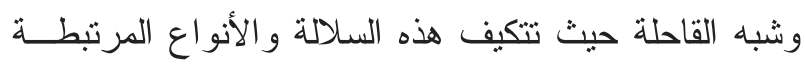
بها بدرجة كبيرة.
هدفت هذه الدراسة إلى عزل وتعريف البكتيريا عاليــة

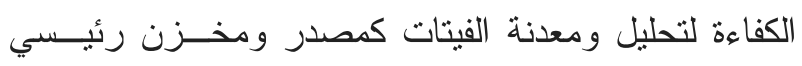
للفسفور العضوي في التربة. وقد تم العـزل مــن التربـــة الجيرية الواقعة في المنطقة الثمالية من مصر و التي تثميز

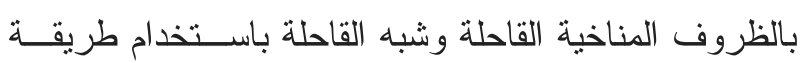

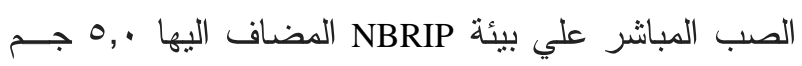
فيتات لكل لتز • وقد تم إختيار احد العزلات للار اسة لفعاليتها

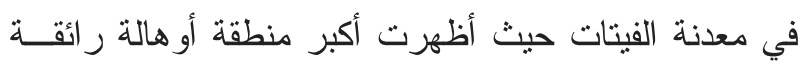

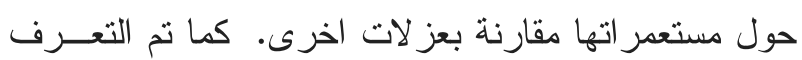

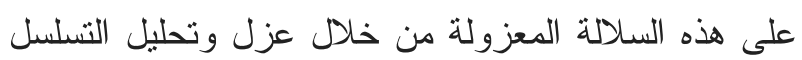

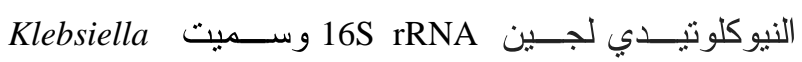
pneumonia strain MK1C

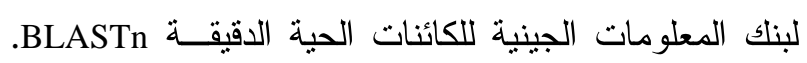

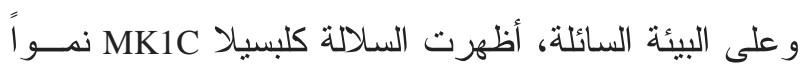

